\title{
Total parenteral alimentation via indwelling umbilical catheters in the newborn period
}

\author{
ROBERT T. HALL and PHILIP G. RHODES \\ From the Department of Pediatrics, Children's Mercy Hospital and University of Missouri School of Medicine, \\ Kansas City, Missouri USA
}

\begin{abstract}
Hall, R. T., and Rhodes, P. G. (1976). Archives of Disease in Childhood, 51, 929. Total parenteral alimentation via indwelling umbilical catheters in the newborn period. Total parenteral alimentation (TPA) was delivered to 80 infants via indwelling umbilical artery and to 9 via indwelling umbilical venous catheters. The primary indication for catheter placement and maintenance was monitoring of arterial blood gases (umbilical venous catheter tip in left atrium) in a group of sick neonates requiring increased inspired oxygen or assisted ventilation. Results were compared with those from 23 infants who had tunnelled jugular catheters for a variety of chronic medical and surgical problems preventing gastric or intestinal feeding. A mean weight gain was achieved in both groups. Mortality and morbidity rates were similar in both groups. The most common complications were infection and thrombotic phenomena. Metabolic complications were few. It is concluded that infusing TPA solutions via indwelling umbilical catheters presents no greater risk than infusion via tunnelled jugular catheters, and provides a method for supplying adequate caloric intake for growth during the acute stage of illness.
\end{abstract}

Adequate nutrition in the neonatal period is considered to be important for subsequent normal growth and development (Winick, 1969; Vahlquist, 1972; Dobbing, 1974; Lloyd-Still et al., 1974). Neonates who present particular difficulties with maintenance of adequate nutrition include the low birthweight infant with respiratory insufficiency, those not tolerating gastric or intestinal alimentation, and many with surgical lesions (especially of the gastrointestinal tract). There are adequate data to support the use of total parenteral alimentation (TPA) via indwelling jugular catheters in infants with surgical and malabsorptive diseases, but its use in the small preterm infant is still in the investigative stage (Das et al., 1970; Asch, Huxtable, and Hays, 1972; Heird and Winters, 1975).

Brans et al. (1974) found an increased daily weight gain in 7 normally grown and 7 intrauterine-growthretarded infants supplemented with TPA solutions. However, the complication rate was high and nutritional advantages compared with controls could not be shown. More encouraging results were reported by Heird and Winters (1975) who studied 14 infants with a mean birthweight of $863 \mathrm{~g}$. A caloric

Received 22 March 1976. intake of greater than $100 \mathrm{cal} / \mathrm{kg}$ per day $(418 \mathrm{~kJ})$ was achieved in 10. A positive nitrogen balance and a $15 \mathrm{~g} / \mathrm{kg}$ per day weight gain were achieved in 8 for an average of 15 days.

Others (Peden and Karpel, 1972; Johnson, Albritton, and Sunshine, 1972; Helmuth, Adam, and Sweet, 1972; Pildes et al., 1973; Bryan et al., 1973; Higgs, Malan, and Heese, 1974; Touloukian, 1975; Abitbol et al., 1975) have cited variable success with many metabolic and catheter complications. Few deal with sick infants, in whom it is most difficult to maintain adequate nutrition, none with total parenteral alimentation via umbilical catheters during the first week of life.

This report concerns the use of TPA solutions in a high-risk group of infants in whom indwelling intravascular catheters were used. All infants were ill during the study period and unable to tolerate gastrointestinal feedings. Our purpose was to test the feasibility of infusing high calorie fluids into already existing lines inserted primarily for monitoring arterial blood gases. These data are compared with those obtained in the study of 23 infants who received TPA via tunneled jugular catheters over the same period of time for more commonly accepted criteria. 


\section{Patients and methods}

In July 1973, a protocol was established for the infusion of TPA fluids via indwelling umbilical catheters. Experience with tunnelled jugular catheters over the previous 3 years in selected surgical and malabsorptive problems provided a baseline experience.

Infants with indwelling umbilical catheters were given TPA infusions beginning at the $3 \mathrm{rd}$ to 5 th days of life if they continued to require mechanical ventilatory assistance or increased inspired oxygen greater than $30 \%$. Routine use of face masks for ventilation rather than endotracheal tubes in almost all patients precluded gavage feedings. Respirators were used for patients with continued respiratory insufficiency (persistent $\mathbf{P C O}_{2}>50 \mathrm{mmHg}$ ) secondary to acute or chronic pulmonary disease, or apnoea requiring bag and mask ventilation more than three times per hour. Feedings were attempted when mechanical ventilation was discontinued. This consisted of one sterile water feeding per gastric gavage, followed by $70 \mathrm{cal} / 100 \mathrm{ml}(293 \mathrm{~kJ})$ formula initially given at $60 \mathrm{ml} / \mathrm{kg}$ per day and increased approximately $20 \mathrm{ml} / \mathrm{kg}$ per day as tolerated until 120$150 \mathrm{cal} / \mathrm{kg}$ per day $(502-627 \mathrm{~kJ})$ was achieved. During the time after the TPA infusions via catheter were discontinued and the patient tolerated insufficient feedings to maintain adequate fluid intake by the gut, supplemental, peripheral intravenous solutions were given. However, data studied were only those obtained while the patient was receiving TPA via indwelling catheters.

Umbilical catheters ( 5 Fr. Argyle catheters, Sherwood Medical Inc., St. Louis, Mo.) had been inserted to obtain blood for arterial blood gas determinations in a group of infants with respiratory insufficiency secondary to respiratory distress syndrome, apnoea, and asphyxia. The catheters were removed when assisted ventilation was discontinued, oxygen requirements fell to ambient air, and enteral feedings started. Arterial catheters terminated with the tip in the descending thoracic aorta above the diaphragm and below the ductus arteriosus. The tip of the umbilical venous catheter was located in the left atrium in patients in whom umbilical artery catheterization was unsuccessful. Tunnelled jugular catheters were placed in the operating room with the tip in the superior vena cava or right atrium. Catheter location was determined by $x$-ray in all cases. Diseases which occurred in those patients who required jugular catheter placement are given in Table $I$.

\section{TABLE I}

\section{Indications for tunnelled jugular catheters}

\begin{tabular}{cl}
\hline Surgical: & 3 gastroschisis \\
& 3 duodenal atresia \\
1 perforated colon (meconium ileus) & 1 diaphragmatic hernia \\
& 1 Hirschsprung's disease \\
Nonsurgical : & 4 malabsorption syndrome \\
& 7 inability to tolerate gavage feedings (as above) \\
& 3 necrotizing enterocolitis. \\
\hline
\end{tabular}

Metabolic data were collected in accordance with the recommendation of Heird et al. (1972b). In addition, arterial blood gases were determined at least three times daily in the umbilical catheter group. Urine specific gravity, Labstix (Ames), and Clinitest (Ames) were determined daily or more frequently as indicated. Blood glucose was estimated three times daily by Dextrostix (Amex) and determined quantitatively for estimates below $45 \mathrm{mg} / 100 \mathrm{ml}(2.5 \mathrm{mmol} / \mathrm{l})$ or greater than 150 $\mathrm{mg} / 100 \mathrm{ml}(8.3 \mathrm{mmol} / \mathrm{l})$. Additional blood glucose determinations were done at random. Metabolic data were collected for each patient receiving TPA infusion during which time parenteral infusion was the sole source of nutrition.

Three TPA solutions were prepared as shown in Table II. The glucose-protein ratio and the electrolyte concentrations were similar in all three solutions. The total caloric content was increased by incremental increases in volumes of $50 \%$ glucose and $8.5 \%$ Freamine added to the solutions prepared in the pharmacy. Patients were started on solution I at $100 \mathrm{ml} / \mathrm{kg}$ per day and advanced to solution II when infusion rates of $150 \mathrm{ml} / \mathrm{kg}$ per day were shown to be well tolerated. Individual adjustments were made for total fluid intake dependent upon estimated losses and the ability of the infant to tolerate the glucose and fluid loads. At the onset of the more concentrated glucose solution, the infusion rate was reduced to permit a gradual increase in the total amount of glucose infused. A similar procedure was used when advancing to solution III.

All solutions were prepared under sterile conditions using a laminar flow hood. Each bottle was cultured for sterility and no bacterial or fungal growth was found. Administration was through a $0.45 \mu \mathrm{m}$ filter; however umbilical lines were interposed by a 3-way stopcock distal to the filter for blood sampling purposes. The infusion bottle and tubing down to the indwelling catheter were changed daily. Stopcocks were changed only when clotted blood appeared to be present in the line immediately adjacent. The insertion site of the umbilical catheters was left open and dry, whereas tunnelled catheters were treated with antibiotic ointment and a sterile dressing change every third day. Biochemical determinations in umbilical catheter patients were obtained on blood obtained through the catheter after clearing with $3 \mathrm{ml}$ blood, except blood glucose which was always obtained from a peripheral vein or heel stick sample. Jugular lines were not violated and blood samples were obtained from peripheral vein or heel prick samples, except for blood gas samples which were obtained from peripheral arteries.

\section{Results}

Data from a total of 112 patients are presented: 80 were fed via the umbilical artery catheter, 9 via the umbilical vein, and 23 via tunnelled jugular catheters. Details of the infants, mean age at onset, duration of infusion, and mean weight gain are given in Table III. Those with umbilical catheter infusion had an earlier age at onset and a shorter 
TABLE II

Composition of 3 TPA solutions (all three solutions contain approximately 136 nonprotein cal/g nitrogen per l fluid)

\begin{tabular}{|c|c|c|c|}
\hline & I & II & III \\
\hline $\begin{array}{l}\text { Calories (kJ) } \\
\text { ^Protein (g) } \\
\text { Glucose (g) } \\
\text { Sodium (mEq) } \\
\text { Potassium (mEq) } \\
\text { tCalcium (mEq) } \\
\text { Magnesium (mEq) } \\
\text { Phosphate (mEq) } \\
\text { Acetate (mEq) } \\
\text { Chlroride (mEq) } \\
\text { Sulphate (mEq) } \\
\text { tGluceptate (mEq) } \\
\text { †MVI concentrate (ml) } \\
\text { Sterile } \mathrm{H}_{2} \text { O qs (ml) } \\
\text { Osmolality (mOsm/l) }\end{array}$ & $\begin{array}{r}510(2132) \\
25 \\
150 \\
30 \\
30 \\
6 \cdot 75 \\
2 \\
15 \\
30 \\
15 \\
2 \\
6 \cdot 75 \\
5 \\
1000 \\
1100\end{array}$ & $\begin{array}{r}680(2842) \\
34 \\
200 \\
30 \\
30 \\
6 \cdot 75 \\
2 \\
15 \\
30 \\
15 \\
2 \\
6 \cdot 75 \\
5 \\
1000 \\
1800\end{array}$ & $\begin{array}{r}850(3553) \\
43 \\
250 \\
30 \\
30 \\
6 \cdot 75 \\
2 \\
15 \\
30 \\
15 \\
2 \\
6 \cdot 75 \\
5 \\
1000 \\
2200\end{array}$ \\
\hline
\end{tabular}

^Freamine (McGaw Lab.) $8.5 \%$ contains $78 \mathrm{~g}$ protein equivalent, $12.5 \mathrm{~g}$ nitrogen, and $47 \mathrm{mEq} \mathrm{Cl} / 1$.

†As calcium glyceptate (the calcium salt of D-glycoheptonic acid) containing $90 \mathrm{mg}$ elemental calcium/5 ml (Abbott Lab.).

¥(U.S., Pharm. Corp) contains 10000 units vitamin A, $500 \mathrm{mg}$ vitamin C, 1000 units vitamin D, 5 units vitamin E, $50 \mathrm{mg}$ thiamine, $10 \mathrm{mg}$ riboflavin, $15 \mathrm{mg}$ pyridoxine, $25 \mathrm{mg}$ dexpanthenol, $100 \mathrm{mg}$ niacin.

\section{TABLE III}

Details of infants

\begin{tabular}{|c|c|c|c|c|c|}
\hline & $\begin{array}{c}\text { No. of } \\
\text { patients } \\
(n=12)\end{array}$ & $\begin{array}{c}\text { Mean birthweight } \\
\pm \mathrm{SE}\end{array}$ & $\begin{array}{l}\text { Age of onset of } \\
\mathrm{TPA} \pm \mathrm{SE}(\mathrm{d})\end{array}$ & $\begin{array}{c}\text { Duration of } \\
\mathrm{TPA} \pm \mathrm{SE}(\mathrm{d})\end{array}$ & $\begin{array}{c}\text { Mean weight } \\
\text { gain (g/d) }\end{array}$ \\
\hline $\begin{array}{l}\text { Umbilical arterial } \\
\text { infusions }(\mathrm{g}) \\
<1200 \\
1200-2000 \\
>2000\end{array}$ & $\begin{array}{l}23 \\
40 \\
17\end{array}$ & $\begin{array}{c}997 \pm 31 \\
1522 \pm 29 \\
2700 \pm 132\end{array}$ & $\begin{array}{l}4 \pm 0.4 \\
4 \pm 0.5 \\
5 \pm 0.9\end{array}$ & $\begin{array}{r}11 \pm 2 \cdot 1 \\
6 \pm 1 \cdot 0 \\
5 \pm 1 \cdot 1\end{array}$ & $\begin{array}{r}6 \\
6 \\
12\end{array}$ \\
\hline $\begin{array}{l}\text { Umbilical venous } \\
\text { infusion (g) } \\
\text { Central venous lines } \\
\text { Surgical } \\
\text { Nonsurgical }\end{array}$ & $\begin{array}{r}9 \\
9 \\
14\end{array}$ & $\begin{array}{l}1709 \pm 288 \\
2605 \pm 207 \\
1474 \pm 177\end{array}$ & $\begin{array}{r}5 \pm 0 \cdot 9 \\
10 \pm 5 \cdot 0 \\
24 \pm 5 \cdot 3\end{array}$ & $\begin{array}{r}6 \pm 1 \cdot 8 \\
11 \pm 1 \cdot 9 \\
16 \pm 3 \cdot 0\end{array}$ & $\begin{array}{l}10 \\
10 \\
10\end{array}$ \\
\hline
\end{tabular}

duration of infusion than the jugular catheter group. Weight gain was observed in all groups which did not vary within the time of infusion.

Mortality and complications in each group are given in Table IV. The overall mortality was 17 out of 112 patients. 6 deaths may have been catheter related as designated in the table by an asterisk. One patient had a thrombus in the aorta and right renal artery, discovered at necropsy, though death occurred only 8 hours after starting TPA infusion. A second patient had a large thrombus in the right atrium associated with a jugular catheter. The remaining 4 deaths in the table were related to sepsis, probably caused by bacteria entering through the catheter.

Ten of the 11 deaths unrelated to catheterization occurred in small preterm infants with respiratory insufficiency who had umbilical artery catheters. Hyaline membrane disease and/or intraventricular haemorrhage were the cause of death in all. The mean birthweight of this group was $1150 \mathrm{~g}$. The eleventh death was an infant weighing $1840 \mathrm{~g}$ with gastroschisis who had a jugular catheter. Necropsy showed massive bowel necrosis. There was no gross or microscopical evidence of damage in the arterial wall at necropsy examination of any of these 11 patients.

The most prevalent complication was infection (Table IV). A total of 21 patients had positive blood cultures, all drawn via a peripheral vein. 12 cultures (10 patients) were due to Staphylococcus epidermidis. The indwelling catheter was 
TABLE IV

Mortality and complications of 112 infants

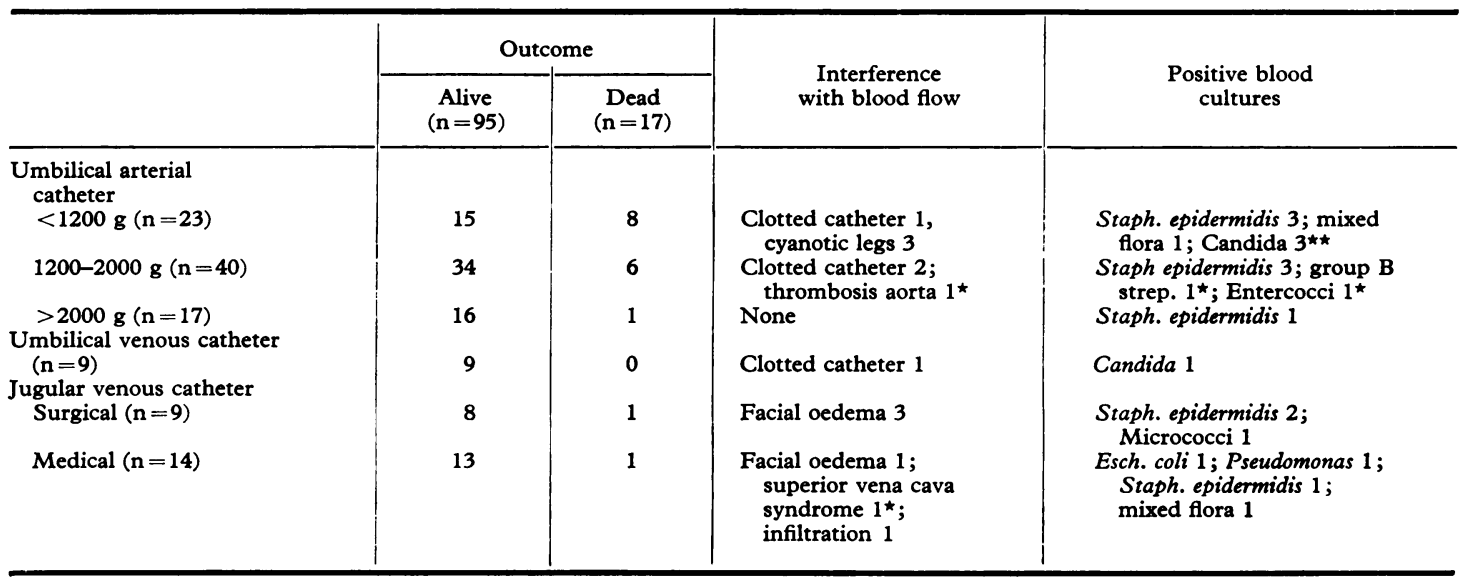

^Death, see text.

removed immediately and methicillin therapy was started in all; however, the organism may have represented skin contamination in some. The one fatality associated with Staph. epidermidis was the patient with a right atrial thrombus. Candida was the next common organism isolated (4 patients) and 2 of these patients died. The incidence of positive blood cultures was similar in patients with umbilical catheters (14/89) compared with those with tunnelled jugular catheters $(7 / 23)$. When calculated in terms of patient-days of therapy, there was approximately one infection per 5 patient-days in both groups.

The other complication was catheter clotting or interference with blood flow. Four umbilical artery catheters clotted: at 8 hours, 24 hours, 7 days, and 30 days after starting TPA infusion. The first of these patients died with a thrombus (mentioned above) extending from the thoracic aorta down to and including the right renal artery. The other 3 have not shown any clinical arterial insufficiency though the catheters were removed without performing arteriograms. Cyanosis disappeared within hours after removal of the umbilical artery catheter in the 3 patients in which it occurred. No sequelae were observed in the one patient with the clotted umbilical venous catheter. 5 patients with jugular catheters developed neck and facial oedema, which gradually subsided in 4 and appeared to be associated with adequate collateral circulation. The one death was associated with the superior vena cava syndrome and Staph. epidermidis sepsis.

Metabolic complications were few and were related primarily to large quantities of glucose infused leading to osmotic diuresis. All were detected by the presence of $2+$ or more glycosuria and significant complications avoided by decreasing the rate of infusion or lowering the concentration of glucose in the infusate. There was a gradual increase in the quantity of glucose infused from a mean of $15 \mathrm{~g} / \mathrm{kg}$ per day on the first day to $20 \mathrm{~g} / \mathrm{kg}$ per day at the end of the first week to a maximum of $25 \mathrm{~g} / \mathrm{kg}$ per day. Protein infusion was increased similarly by virtue of the fixed glucose-protein (Table II). This resulted in an increase in mean caloric intake from $60 \mathrm{cal} / \mathrm{kg}$ per day to $100 \mathrm{cal} / \mathrm{kg}$ per day $(251-418 \mathrm{~kJ})$.

These infusions were well tolerated as indicated by serial determination of serum electrolytes, arterial blood $p \mathrm{H}$, and $\mathrm{PCO}_{2}$, serum glucose, urea nitrogen, and ammonia. All mean values during the infusions were normal except for the appearance of a mild compensated respiratory acidosis during the last 2 weeks in a few patients in whom infusions were continued. This gradual rise in $\mathrm{PcO}_{2}$ can be attributed to infants with chronic pulmonary disease. One patient developed a transient hyperchloraemic metabolic acidosis which was easily corrected by the substitution of acetate for chloride in the infusion. A second patient had a blood ammonia of $274 \mathrm{mg}$ / $100 \mathrm{ml}$ on the first day which resolved spontaneously. A gradual increase in serum urea nitrogen was observed from a mean of $15 \mathrm{mg} / 100 \mathrm{ml}$ $(5.4 \mathrm{mmol} / \mathrm{l})$ at the start of the infusion to $22 \mathrm{mg} /$ $100 \mathrm{ml}(7.9 \mathrm{mmol} / \mathrm{l})$ at the end of the second week. No adverse effects were observed. 


\section{Discussion}

This study shows that adequate caloric intake for weight gain can be achieved in sick newborn infants using TPA solutions administered via indwelling umbilical catheters inserted for monitoring arterial blood gases. Total parenteral alimentation was begun at an average of 4.5 days of age and continued for a mean of 7 days (range 1-44 days), after which the umbilical catheter could be removed and oral or gavage feedings started with supplemental intravenous fluids.

Although the morbidity rate was high with regard to both infection $(14 / 89,16 \%)$ and interruption of blood flow $(8 / 89,9 \%)$, it was no higher than in those in whom jugular catheters were used $(7 / 32,30 \%$ infection, and $6 / 23,26 \%$ thrombosis). The apparent higher incidence of complications in the jugular catheter group disappears when compared on the basis of complication rate per patient day of therapy. These complication rates are also similar to those of long-term umbilical vessel catheterization without TPA infusion (Balagtas, et al., 1971; Peter, Lloyd-Still, and Lovejoy, 1972; Van Vliet and Gupta, 1973; Bard et al., 1973; Goetzman et al., 1975). As noted by Heird and Winters (1975), increasing experience and meticulous attention to catheter care can decrease complications of infection. Addition of heparin to the infusate may reduce thrombotic complications and has become part of our routine since completion of this study, though no data are yet available to determine the value of this procedure.

Mortality rates were acceptable and compare favourably with infants of similar birthweight with severe respiratory distress syndrome from our hospital (Rhodes, Hall, and Leonidas, 1975). In only one death could the umbilical artery catheter be clearly implicated (thrombosis of aorta) and it is likely that the TPA solution did not play a role in the thrombus formation.

The lack of metabolic complications is likewise encouraging, though careful monitoring of Dextrostix (or blood sugar), urine sugar and specific gravity, serum electrolytes, and other parameters were useful in preventing serious complications. Metabolic acidosis was not a significant complication except in one patient in spite of the high chloride and 'cationic amino acids' present in Freamine (McGaw, Laboratories, Glendale, Calif.) (Heird et al., 1972a). The rarity of this complication is probably due to the substitution of acetate for chloride in the commercial preparation of Freamine II.

High urea nitrogen was observed throughout the study and these data as well as those of Heird and Winters (1975) and Chen, Ohashi, and Kasai (1974) suggest that much lower protein levels can be used to achieve a positive nitrogen balance and effect complete utilization of infused protein. In spite of the relatively high levels of nitrogen infused and serum urea nitrogen observed, no complications of 'isomolar coma' occurred as described by Touloukian (1975). However, our current practice is to use a TPA solution which has a lower quantity of protein and contains approximately 200 nonprotein calories $/ \mathbf{g}$ nitrogen.

These data provide a baseline for a controlled prospective study comparing the use of TPA solutions via indwelling umbilical catheters compared with other methods of parenteral therapy in infants not able to tolerate oral or gavage feeds. These data were not controlled and cannot be construed as evidence that infusion of TPA fluids via indwelling umbilical catheters is the best method of providing adequate calories during acute or chronic pulmonary insufficiency. Controlled data are required to determine whether transpyloric feedings, peripheral infusions of high caloric fluids, or other methods are more effective with a lower complication rate. Indeed, there are no controlled data to indicate that weight gain and growth is critical for improved morbidity and mortality rates during the first 2 to 3 weeks of life, though it is known that prolonged protein-caloric malnutrition can affect subsequent brain growth (Winick, 1969). Studies using large volumes of low solute-containing fluids (Fox and Krasna, 1973) and intravenous lipid solutions (Coran, 1974; Cashore, Sedaghatian, and Usher, 1975) given via peripheral veins appear promising. Since long-term results showing the efficacy of weight gain in the newborn period achieved by any method of alimentation are not yet available, this factor should be considered in the design of any future study.

The authors express their appreciation to Ms. Gay Kurth for her assistance.

\section{REFERENCES}

Abitbol, C. L., Feldman, D. B., Ahmann, P., and Rudman, D. (1975). Plasma amino acid patterns during supplemental intravenous nutrition of low-birth-weight infants. fournal of Pediatrics, 86, 766.

Asch, M. J., Huxtable, R. F., and Hays, D. M. (1972). High calorie parenteral therapy in infants and children. Archives of Surgery, $104,434$.

Balagtas, R. C., Bell, C. E., Edwards, L. D., and Levin, S. (1971) Risk of local and systemic infections associated with umbilical vein catheterization: a prospective study in 86 newborn patients. Pediatrics, 48, 359.

Bard, H., Albert, G., Teasdale, F., Doray, B., and Martineau, B. (1973). Prophylactic antibiotics in chronic umbilical artery catheterization in respiratory distress syndrome. Archives of Disease in Childhood, 48, 630. 
Brans, Y. W., Sumners, J. E., Dweck, H. S., and Cassady, G. (1974) Feeding the low birthweight infant: orally or parenterally? Preliminary results of a comparative study. Pediatrics, 54, 15.

Bryan, M. H., Wei, P., Hamilton, J. R., Chance, G. W., and Swyer, P. R. (1973). Supplemental intravenous alimentation in lowbirth-weight infants. Fournal of Pediatrics, 82, 940.

Cashore, W. J., Sedaghatian, M. R., and Usher, R. H. (1975). Nutritional supplements with intravenously administered lipid, protein hydrolysate, and glucose in small premature infants. Pediatrics, 56, 8.

Chen, W. J., Ohashi, E., and Kasai, M. (1974). Amino acid metabolism in parenteral nutrition: with special reference to the calorie: nitrogen ratio and the blood urea nitrogen level. Metabolism, 23, 117.

Coran, A. G. (1974). Total intravenous feeding of infants and children without the use of a central venous catheter. Annals of Surgery, 179, 445.

Das, J. B., Filler, R. M., Rubin, V. G., and Eraklis, A. J. (1970). Intravenous dextrose-amino-acid feeding: the metabolic response in the surgical neonate. Fournal of Pediatric Surgery, $5,127$.

Dobbing, J. (1974). The later growth of the brain and its vulnerability. Pediatrics, 53, 2.

Fox, H. A., and Krasna, I. H. (1973). Total intravenous nutrition by peripheral vein in neonatal surgical patients. Pediatrics, $52,14$.

Goetzman, B. W., Stadalnik, R. C., Bogren, H. G., Blankenship, W. J., Ikeda, R. M., and Thayer, J. (1975). Thrombotic complications of umbilical artery catheters: a clinical and radiographic study. Pediatrics, 56, 374.

Heird, W. C., and Winters, R. W. (1975). Total parenteral nutrition. The state of the art. Fournal of Pediatrics, 86, 2.

Heird, W. C., Dell, R. B., Driscoll. J. M., Jr., Grebin, B., and Winters, R. W. (1972a). Metabolic acidosis resulting from intravenous alimentation mixtures containing synthetic amino acids. New England fournal of Medicine, 287, 943.

Heird, W. C., Driscoll, J. M., Jr., Schullinger, J. N., Grebin, B., and Winters, R. W. (1972b). Intravenous alimentation in pediatric patients. Fournal of Pediatrics, 80, 351.
Helmuth, W. V., Adam, P. A. J., and Sweet, A. Y. (1972). The effects of protein hydrolysate-monosaccharide infusion on lowbirth-weight infants. Fournal of Pediatrics, 81, 129.

Higgs, S. C., Malan, A. F., and Heese, H. De V. (1974). A comparison of oral feeding and total parenteral nutrition in infants of very low birthweight. South African Medical fournal, 48, 2169 .

Johnson, J. D., Albritton, W. L., and Sunshine, P. (1972). Hyperammonemia accompanying parenteral nutrition in newborn infants. Fournal of Pediatrics, 81, 154.

Lloyd-Still, J. D., Hurwitz, I., Wolff, P. H., and Schwachman, H. (1974). Intellectual development after severe malnutrition in infancy. Pediatrics, 54, 306.

Peden, V. H., and Karpel, J. T. (1972). Total parenteral nutrition in premature infants. Fournal of Pediatrics, 81, 137

Peter, G., Lloyd-Still, J. D., and Lovejoy, F. H., Jr. (1972). Local infection and bacteremia from scalp vein needles and polyethylene catheters in children. Fournal of Pediatrics, 80, 78.

Pildes, R. S., Ramamurthy, R. S., Cordero, G. V., and Wong, P. W. K. (1973). Intravenous supplementation of L-amino acids and dextrose in low-birthweight infants. Fournal of Pediatrics, 82, 945.

Rhodes, P. G., Hall, R. T., and Leonidas, J. C. (1975). Chronic pulmonary disease in neonates with assisted ventilation. Pediatrics, 55, 788.

Touloukian, R. J. (1975). Isomolar coma during parenteral alimentation with protein hydrolysate in excess of $4 \mathrm{gm} / \mathrm{Kg} /$ day. fournal of Pediatrics, 86, 270.

Vahlquist, B. (1972). Early malnutrition and brain development. Acta Paediatrica Academiae Scientiarum Hungaricae, 13, 309.

Van Vliet, P. K. J., and Gupta, J. M. (1973). Prophylactic antibiotics in umbilical artery catheterization in the newborn. Archives of Disease in Childhood, 48, 296.

Winick, M. (1969). Malnutrition and brain development. Fournal of Pediatrics, 74, 667.

Correspondence to Dr. Robert T. Hall, Neonatal Intensive Care Unit, Children's Mercy Hospital, 24th and Gillham, Kansas City, Missouri, 64108 USA. 